\title{
Modificación de la legislación sustantiva vinculada al lavado de activos
}

\section{Modification of the substantive law related to money laundering}

Segundo Félix Quesquén Ríos* http://dx.doi.org/10.21503/lex.v11i12.28

* Abogado por la Universidad Inca Garcilaso de la Vega, Máster en Derecho Civil por la Universidad Alas Peruanas, estudiante del Doctorado en Derecho y Ciencia Política en la Universidad Nacional Mayor de San Marcos, Diplomado por el Ilustre Colegio de Abogados del Callao en "Derecho Penal y Económico: Delitos Tributarios y Aduanero", Diplomado Especializado en el Código Procesal Penal del 2008 y Técnicas de Litigación Oral por la UAP, Catedrático de Derecho Procesal Penal de la Universidad Alas Peruanas.
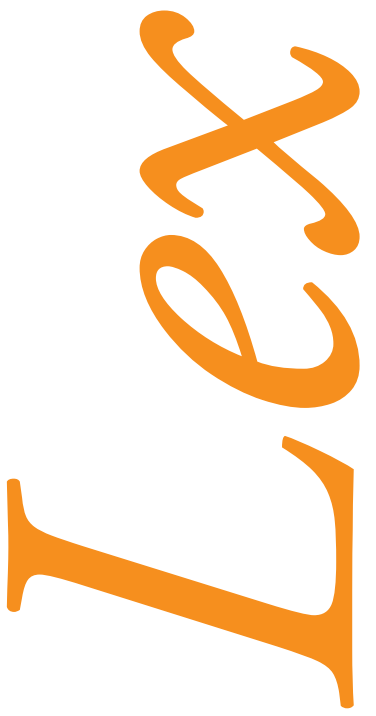



\section{RESUMEN}

El presente trabajo tiene como objetivo hacer un análisis a la modificación de la legislación sustantiva tipificada en el Decreto Legislativo $1106,{ }^{1}$ norma que regula la investigación, procesamiento y sanción de personas naturales y jurídicas vinculadas al lavado de activos y otros delitos relacionados con el crimen organizado, con particular énfasis en la minería ilegal.

Palabras clave: legislación sustantiva, lavado de activos.

\section{ABSTRACT}

This work has as an objective: do an analysis to the modification of the categorized substantive law in the Executive Order 1106, regulation that controls the research, processing and sanction of linked natural and juridical people to money laundering and other related misdeeds to the organized crime with particular emphasis on the illegal mining.

Key words: substantive legislation, money laundering.

1 Decreto Legislativo 1106. Decreto Legislativo de Lucha Eficaz contra el Lavado de Activos y otros delitos relacionados a la Minería Ilegal y Crimen Organizado. Publicado en el Diario Oficial El Peruano, el 19 de abril del 2012. 



\section{INTRODUCCIÓN}

El mundo cambia día a día. La globalización de las economías arrastra con ello los problemas sociales, económicos y políticos. Uno de los delitos que se ha posicionado en las naciones y se ha internacionalizado es el delito de lavado de activos.

Las naciones han buscado combatir el lavado de activos agrupándose con la finalidad de combatir este ilícito penal. Una de tales grupos es el Gafisud, una organización intergubernamental de base regional que agrupa a los países de América del Sur para combatir el lavado de activos y la financiación del terrorismo. Además de las organizaciones nacidas en el mundo para batallar el lavado de dinero, también se han firmado tratados internacionales en los cuales el blanqueo de activos tiene protagonismo. Su objetivo no es otro que intentar supervisar todos aquellos fondos de procedencia sospechosa y aplicar fuertes sanciones económicas y penales a los implicados.

El Estado Peruano, en aras de obtener un control eficaz en el lavado de activos, deroga la Ley $\mathrm{N}^{\circ} 27765$ del 27 de Junio del 2002 y expide el Decreto Legislativo $\mathrm{N}^{\circ} 1106$, publicada en el Diario Oficial el Peruano el 19 de abril del 2012, vigente a los 15 días de su publicación. Norma "De Lucha Eficaz contra el Lavado de Activos y otros Delitos Relacionados a la Minería Ilegal y Crimen Organizado" A poco más de un año y seis meses de vigencia de la norma en comento, hemos visto que no ha erradicado totalmente la minería ilegal.

Debemos precisar que la expedición de la norma en comento se justificó en el preocupante incremento de la criminalidad vinculada con las actividades de minería ilegal, las cuales, además de dañar gravemente el ecosistema, la vida y la salud de las personas, representan también una considerable desestabilización del orden socioeconómico, pues estas actividades ilícitas se encuentran estrechamente ligadas con el blanqueo de activos o de capitales, que buscan dar una apariencia de legalidad a bienes de origen delictivo e introducirlos indebidamente el tráfico económico lícito. ${ }^{1}$

1 Justificación del Decreto Legislativo $1086^{\circ}$, publicado en el Diario Oficial El Peruano del 19 de abril del 2012. 


\section{ASPECTOS CRIMINOLÓGICOS DEL DELITO DE LAVADO DE ACTIVOS}

El problema criminológico que plantea el lavado de activos ha generado el nacimiento de la denominada criminalidad organizada. Uno de los factores para que esto haya ocurrido es la globalización de las relaciones económicas que también han afectado al delito y a sus formas de aparición; lo que trae como necesidad que también se emprenda una lucha globalizada por parte de los Estados en contra de la criminalidad organizada por ser un tipo de criminalidad no convencional, en la medida que no existen marcos normativos expresos que la castiguen y combatan de manera eficiente, resultando muchas veces sus actuaciones ilícitas atípicas, teniendo en cuenta que este tipo de criminalidad, por lo general, se da utilizando a la persona jurídica como agente activo del delito, ente abstracto dentro del cual alternan no solo los directivos y representantes legales de la misma, sino que para la realización de sus actos delictivos cuentan con la participación de gente capacitada en los distintos conocimientos científicos y técnicos puestos al servicio del crimen, y que al existir vacíos en los marcos normativos, muchos de los sujetos que participan en el delito a través de la persona jurídica no son castigados, siendo únicamente sancionados sus representantes legales, por lo que surge la necesidad y preocupación de hacer una reingeniería jurídica de la responsabilidad penal, institución que hace más de doscientos años nos viene ayudando en el combate de la criminalidad, y que, ante la aparición como sujeto de derecho de la persona jurídica, es necesario que los juristas vía el Derecho comparado delineen un nuevo tipo de responsabilidad penal donde se incluya expresamente a la persona jurídica, y no quedarse en el intento, como ha sucedido en nuestra legislación en el Artículo 105 del Código Penal, y que el Decreto Legislativo $\mathrm{N}^{\circ} 1106$ continua de manera consecuente.

\section{EL DELITO DE LAVADO DE ACTIVOS EN EL DERECHO PENAL PERUANO²}

Al aprobarse en diciembre de 1988 la Convención de las Naciones Unidas contra el tráfico ilícito de Estupefacientes y Sustancias Psicotrópicas, el Perú ingresaba a una etapa de cambios legislativos, y, consecuentemente, a una sustitución del Código Penal de 1924, que tipificaba el delito de tráfico ilícito de drogas en una legislación especial promulgada con el Decreto Ley No 22095 del año 1978, el mismo que había sufrido sucesivas enmiendas. Acto seguido, en la medida que la Convención de Viena se hallaba aún pendiente de aprobación en el Parlamento, los proyectos del Código Penal de 1990 y de enero del 91 así como los códigos penales promulgados en abril de 1991 no incorporaron en su articulado disposiciones referidas a la criminalización del lavado de activos o dinero. El Código Penal de 1991 lo único que hizo fue el cambio de tipo básico del delito (artículo 296). Sin embargo, el Estado Peruano en mayo del 1991 firmó un compromiso bilateral con los Estados Unidos de Norteamérica, reflejado en el Decreto Supremo $N^{\circ} 100-01-\mathrm{PCM}$, comprometiéndose a la lucha contra el narcotráfico y el

${ }^{2}$ César Hinostroza Pariachi. El delito de lavado de activos. Editorial Grijley, 2009, p. 97-98. 
lavado de fondos ilícitos. Así mismo, el Perú participó en el grupo de expertos que convocó la CICAD-OEA para la elaboración del Reglamento Modelo de legislación continental que recomendó la unión de Ixtapa, así como la ratificación de Viena por el Congreso peruano del 23 de setiembre de 1991.

De lo antes expuesto, nuestro país, en busca de mejorar nuestra legislación penal sobre lavado de activos, expide el Decreto Legislativo 736, promulgado el 08 de noviembre de 1991, adicionando dos artículos importantes en la sección II del Capítulo III, del Título XII del Código Penal, sobre tráfico ilícito de drogas. Estos famosos tipos penales contemplados en los artículos "296-A" y "297-B" tuvieron como función político-penal criminalizar los actos de lavado de dinero provenientes del narcotráfico.

Ahora bien, en cuanto a la técnica legislativa, el nuevo delito fue incorporado a través de dos modalidades de ejecución. La primera, prevista en el Art. 296-A, se relacionaba con los actos de conversión, transferencia y ocultamiento de los bienes originados o derivados del tráfico ilícito de drogas, mientras que la segunda, tipificada en el Art. 296-B, estaba dedicada a los actos de lavado de dinero a través del sistema financiero o mediante procedimientos de repatriación de capitales. Sin embargo, la redacción de ambos tipos legales era bastante engorrosa y evidenciaba claramente una intención omnicomprensiva por parte de nuestro legislador. Esto también abona en la falta de correspondencia directa entre la evolución de nuestra legislación en esta materia y el desarrollo normativo internacional, puesto que las hipótesis típicas del lavado de dinero estaban mucho mejor estructuradas en la convención de Viena, y las fórmulas de tipificación de los proyectos de reglamento Modelo de la CICAD eran distintas a las nuestras. ${ }^{3}$

Al ser el Art. 296-A fiel copia de la ley Argentina Nro. 23737, Art. 25ํㅜ reprimía cualquier intervención en la inversión, venta, pignoración, transferencia o cesión de ganancias, cosas o bienes o beneficio económico de un delito, así como la compra, ocultamiento, receptación de dichas ganancias, cosas, bienes o beneficios, siempre que hubiere conocido su origen ilícito o lo hubiere sospechado, sin dejar de lado el Art. 296-B, de similar situación a la norma argentina con respecto a la suspensión de la reserva bancaria o tributaria, así como el uso restringido y especifico de la información obtenida con dicha medida. Dicho articulado fue duramente criticado por cuanto contaba con normas severas.

Posteriormente, el 11 de febrero de 1991 se promulgó la ley 25404, que buscaba incorporar las actividades del lavado de dinero dentro del rubro correspondiente de los delitos contra el patrimonio en la modalidad de receptación (crimen receptorum). Lo que esta disposición en

Víctor Roberto Prado Saldarriaga. El delito de lavado de dinero. Su tratamiento penal y Bancario en el Perú. Lima: IDEMSA, 1994. 
realidad hizo fue modificar el Art. $195^{\circ}$ del Código Penal referido a la figura de la receptación, subsumiendo ambos casos en uno solo, con la finalidad de que ambas conductas (cuando se tratara de bienes de propiedad del Estado destinados a los servicios público y cuando el agente se dedicara al comercio de bienes provenientes de acciones delictivas) aparecieran una seguida de otra. El segundo párrafo de la citada disposición hacía la salvedad de que cuando se trataba de bienes provenientes del tráfico ilícito de drogas o del terrorismo la penalidad se agravaba. ${ }^{4}$

En el año 1991 se promulgó el Decreto Ley No 25428, que lo único que hizo fue aumentar la pena máxima establecida por el Código Penal vigente a esa fecha; y el 20 de agosto de 1993, se promulgó la Ley $\mathrm{N}^{\circ} 26223$, que modificó el Art. 296-B y otorgó como pena capital la cadena perpetua para este tipo de delito.

Mediante Ley 27693, del 12 de abril del 2002, se crea la Unidad de Inteligencia Financiera, entidad gubernamental encargada del análisis, el tratamiento y la transmisión de información al Ministerio Público en caso de detectar la realización de actividades sospechosas de lavado de activos.

La Ley $\mathrm{N}^{\circ} 27765$, del 27 de junio del 2002, salva muchas de las incongruencias que presentaban los artículos $296^{\circ}$-A 296-B del Código Penal, actualmente derogados.

La reforma introducida por el Decreto Legislativo 986 del 27 de junio del 2007 significó una delimitación de algunas modalidades típicas previstas en los artículos $1^{\circ}$ y $2^{\circ}$ de la Ley $\mathrm{N}^{\circ}$ 27765. Así también en virtud de esta reforma legislativa se agravaron las penas para modalidades agravadas del artículo 3 de la referida norma legal. Antes de que se realice esta reforma, los delitos fuentes, según la enumeración del artículo 6 de la Ley $\mathrm{N}^{\circ}$ 27765, eran el tráfico ilícito de drogas, los delitos contra la administración pública, secuestro y proxenetismo, defraudación tributaria, los delitos aduaneros y "otros que generen ganancias ilegales". Así pues, uno de los principales aspecto de la reforma legislativa se refirió a los delitos fuentes, encontrándose entre estos los delitos de terrorismo, secuestro, extorsión, trata de personas, tráfico ilícito de migrantes, delitos aduaneros, defraudación tributaria, delitos contra la administración pública y aquellos que afectan el patrimonio en su modalidad agravada.

El Decreto Legislativo No 1106, publicado el 19 de abril del 2012, ha sustituido la antigua ley penal contra el lavado de activos, Ley 27765. Esta innovación legislativa pretende continuar con la ardua lucha contra el lavado de activos, ampliando para ello los márgenes de punibilidad para incluir a los ilícitos penales que tengan su origen en la minería ilegal y el crimen organizado.

4 Luis Lamas Puccio. "La ley penal contra el lavado de activos". En: Revista del Foro. Año XC, № 1, Colegio de Abogados de Lima, 2004, pp. 384-385. 
La nueva ley puede analizarse desde diferentes puntos de vista: las cuestiones de naturaleza sustantiva, los aspectos probatorios, preventivos y de control administrativo con potencial trascendencia punitiva, en razón de que con esta Ley se producen modificaciones en la legislación sustantiva y procesal que regula la investigación, procesamiento y sanción de personas, naturales y jurídicas, vinculadas con el lavado de activos y otros delitos relacionados al crimen organizado, con particular énfasis en la minería ilegal.

\section{DEFINICIÓN DEL DELITO DE LAVADO DE ACTIVOS}

En la generalidad de las declaraciones internacionales, como la Convención de Viena, y en la particularidad de cada legislación, es posible encontrar una idea rectora en aquellos comportamientos que merecen ser comprendidos en este tipo penal. Así, observamos que el lavado de activos se configura mediante la realización de actos que consisten en ocultar o encubrir la procedencia delictiva de capitales o valores económicos, introduciéndolos en la economía formal. El propósito del agente debe orientarse a conseguir la circulación y consiguiente inserción en la economía de esos capitales de origen lícito. Este proceso es conocido también en la legislación y doctrina extranjera como blanqueo de capitales. Debemos destacar que en todo acto de lavado está implícita la idea del ocultamiento de la génesis en la adquisición de un bien, dinero, ganancias, efecto o capital. ${ }^{5}$

Lavado de dinero o de activos significa la conversión de dinero clandestino en dinero de curso legal, dinero sucio en dinero limpio, dinero escondido en dinero circulante en instrumentos financieros, mediante su colocación en el sistema bancario o la conversión de estas ganancias en otros bienes, transfiriéndolo con el propósito de ocultar su origen, encubrir su naturaleza y su propiedad, desvaneciendo toda huella y rastro de su procedencia ilícita para evitar su incautación o decomiso. Es toda operación patrimonial, comercial o financiera con el propósito de legalizar los recursos, bienes y servicios provenientes de actividades ilícitas. ${ }^{6}$

\section{MINERÍA ILEGAL Y MINERÍA INFORMAL}

Calderón Velarde ${ }^{7}$ refiere que para entender mejor la ratio decidendi de la tipificación del delito de minería ilegal, debemos hacer la diferenciación entre minería ilegal y minería informal, dado que aunque ambas se relacionan, existen ciertas particularidades que han permitido definir la estrategia estatal para abordar la problemática de cada una de ellas. Partimos de lo dispuesto por el Decreto Legislativo $\mathrm{N}^{\circ} 1100$, publicado el 18 de febrero del 2012, que estableció la definición de lo que en el ámbito administrativo debía entenderse por

César Hinostroza Pariachi. El delito de lavado de activos. Delito fuente. Lima: Editora Jurídica Grijley, 2009, p. 37.

6 Juan B. León Gamarra. El contador público en la investigación del lavado de activos en el Perú. Lima: L y F Ediciones Jurídicas, 2003, p. 11.

7 Leonardo Calderón Velarde. "Apuntes sobre el delito de minería ilegal en el Perú a poco más de un año desde su tipificación”. En: Gaceta Penal y Procesal Penal. Tomo 49, julio 2013, pp. 158-159. 
minería ilegal, al señalar que el título de concesión minera no faculta a iniciar actividades, sino que es necesario tramitar otro tipo de autorizaciones, permisos y licencias posteriores a este título firme, por lo que el hecho de realizar actividades sin contar con esas autorizaciones la convierte en minería ilegal.

Refiere el autor, con posterioridad, que dicha definición ha sido sustituida por la dispuesta en el Decreto Legislativo $N^{\circ} 1105$, de fecha 19 de abril del 2012, la cual refiere que minería ilegal es aquella actividad minera ejercida por una persona natural o jurídica o grupo de personas organizadas, usando maquinarias que no corresponde a su estratificación o sin cumplir con las exigencias normativas (administrativas, técnicas, sociales y medioambientales) o desarrolla sus actividades en zonas en las que esté prohibida su ejecución. Así mismo, este dispositivo legal precisa que debe entenderse como minería informal la realizada bajo estos mismos presupuestos, pero con diferencia respecto al lugar donde es ejercida dicha actividad, esta debe ser desarrollada en zonas no prohibidas para la actividad minera, siempre y cuando los sujetos activos hayan iniciado un proceso de formalización. A diferencia de los conceptos brindados en los citados decretos, el Decreto Legislativo $N^{\circ} 1102$ realiza una conceptualización de lo que debe entenderse desde el punto de vista penal como minería ilegal, puntualizando que se trata de una actividad minera no autorizada, y condicionándola a la existencia de un daño o un peligro de daño al medio ambiente, sus componentes, la calidad ambiental y la salud ambiental.

Concluye el citado autor, en primer lugar, que la minería ilegal es practicada en una dimensión empresarial, empleando maquinaria industrial y, tal como se señaló previamente, sin contar con las debidas autorizaciones de la autoridad competente para poder operar; y en segundo lugar, que la minería informal es aquella minería realizada sin haber obtenido los títulos habilitantes conexos a la concesión minera, por sujetos con fines de subsistencia y que generalmente son empleados por la minería ilegal como mano de obra. Ambas se presentan de forma conjunta, pues la primera se aprovecha de la segunda; sin embargo, la estrategia diferenciada apunta a la indicación de la minería ilegal buscando la formalización de la minería informal.

\section{DECRETO LEGISLATIVO N 1106 “LEY PENAL DE LAVADO DE ACTIVOS”}

\section{Bien jurídico protegido}

Uno de los grandes problemas de la doctrina es la determinación del bien jurídico protegido. Las posiciones suelen resumirse en dos grandes grupos: los que consideran que estamos ante un delito pluriofensivo, y los que sostienen que nos encontramos ante una figura cuyo objeto de tutela se limita a un solo bien jurídico. 
Bramont-Arias Torres ${ }^{8}$ señala que el lavado de activos es un delito pluriofensivo, en el que el bien jurídico principal de protección sería el orden socioeconómico, y dentro del mismo, específicamente, el tráfico ilícito de bienes que debe imperar en toda sociedad, el cual se vería afectado con la circulación de bienes ilícitos

Para el ilustre jurista Hinostroza Pariachi," el objeto de protección de este tipo penal se extiende a varios ámbitos. El lavado de activos es una figura delictiva caracterizada por la complejidad de su objeto de tutela. No se limita únicamente a la protección de la administración de justicia o del orden socioeconómico, pues comprende ambos sectores. En suma, lo que mediante este tipo penal se protege es la estabilidad del sistema económico garantizando su funcionalidad. Desde nuestro punto de vista, estos son los bienes jurídicos protegidos:

- Orden socioeconómico.

- Administración de justicia.

- $\quad$ Fidelidad en el tráfico económico.

\section{Tipicidad objetiva en el delito de lavado de activos}

\section{Actos de conversión y transferencia}

El artículo $1^{\circ}$ del Decreto Legislativo 1106 tipifica como delito "los actos de conversión y transferencia”. El texto legal de dicho artículo es el siguiente:

"El que convierte o transfiere dinero, bienes, efectos o ganancias cuyo origen ilícito conoce o debía presumir, con la finalidad de evitar la identificación de su origen, su incautación o decomiso, será reprimido con pena privativa de la libertad no menor de ocho ni mayor de quince años y con ciento veinte a trescientos cincuenta días multa”.

El artículo bajo comentario se configura como un tipo legal alternativo y común definiendo dos conductas delictivas, que son: La conversión y la transferencia. La norma no distingue que una misma persona pueda realizar los dos actos a la vez.

Los actos de conversión involucran todas las formas posibles de colocación o movilización primaria de dinero líquido, incluso podemos considerar dentro de ellas a la recolección del dinero sucio, siempre que ella la ejecute el agente de la operación del lavado. En la

8 Luis Alberto Bramont-Arias Torres. "Algunas precisiones referentes a la Ley Penal contra el Lavado de Activos. Ley 27765, 27/06/2002”. En: Estudios penales. Libro homenaje al profesor Luis Alberto Bramont-Arias. Lima: San Marcos, p. 521.

9 César Hinostroza Pariachi. El delito de lavado de activos. Delito fuente. Lima: Editora Jurídica Grijley, 2009, p. 103. 
materialización de las conductas de conversión de activos, se recurre a varias técnicas de estructuración y fraccionamiento como el uso de "pitufos", con la finalidad de eludir los controles preventivos. El agente además utiliza pequeñas inversiones en la adquisición de inmuebles o automóviles. También es común que se convierta el dinero ilícito a través del uso de servicios como casinos, restaurantes, etc. ${ }^{10}$

Los actos de transferencia buscan tipificar operaciones de lavado posteriores a la etapa de colocación, es decir, todas aquellas que corresponden a la etapa de intercalación u estratificación donde el objetivo del agente es alejar los capitales o bienes convertidos de su origen ilícito y de su primera transformación. ${ }^{11}$

De lo antes expuesto, concluimos que constituyen supuestos típicos de conversión y transferencia todos los actos o negocios jurídicos, de cualquier clase, que involucran la translación de dominio, la posesión o la tenencia de dinero y ganancias de origen ilícito, sea que se realicen a título oneroso o gratuito.

\section{Actos de ocultamiento y tenencia}

El artículo $2^{\circ}$ del Decreto Legislativo 1106 tipifica como delito los "actos de ocultamiento y tenencia”. El texto legal de dicho artículo es el siguiente:

"El que adquiere, utiliza, guarda, administra, custodia, recibe, oculta o mantiene en su poder dinero, bienes, efectos o ganancias, cuyo origen ilícito conoce o debía presumir, con la finalidad de evitar la identificación de su origen, su incautación o decomiso, será reprimido con pena privativa de la libertad no menor de ocho ni mayor de quince años y con ciento veinte a trescientos cincuenta días multa”.

Adquirir es sinónimo de comprar, por ende, es a título oneroso, por ejemplo: la persona adquiere una casa que se construyó con el dinero perteneciente al tráfico ilícito de drogas. Utilizar es aprovecharse de un bien mueble o inmueble por ejemplo de un vehículo o casa, sin necesidad de haberlo adquirido o alquilado. Guardar, custodiar, ocultar o mantener en su poder son variaciones respecto a la posesión de un bien. Recibir es tomar algo que se nos ha dado; en este caso, se aplicará a los supuestos a título gratuito, puesto que los casos a título oneroso encajan en el verbo adquirir. ${ }^{12}$

En la descripción normativa también encontramos un tipo penal alternativo, y en ello también se tipifica un delito común donde el sujeto activo puede ser cualquier persona. Las

\footnotetext{
Víctor Roberto Prado Saldarriaga. Lavado de activos y financiación del terrorismo. Editorial Grijley, 2007, p. 142. Ibidem. p. 143.

Jorge Pérez López. "Lavado de activos y aspectos sustantivos del decreto legislativo N 1106". En: Gaceta Penal y Procesal Penal. No 35, mayo 2012, pp. 58-59.
} 
conductas típicas realizadas por el sujeto activo son el ocultamiento y la tenencia. No existen limitaciones para que el mismo agente, eso sí en momentos secuenciales, pueda ejecutar los dos comportamientos. Sin embargo, las tipologías del delito reportan siempre la intervención sucesiva e independiente de distintos sujetos. ${ }^{13}$

Los actos de ocultamiento y tenencia son aquellos que representan en la legislación penal a la fase final del proceso de lavado de activos. Esta es la etapa que conocemos como de integración. Se trata, entonces, de conductas que tienen lugar una vez que los activos han adquirido una ficticia apariencia de legalidad, la que les fue gestada por los actos anteriores de conversión y transferencia. ${ }^{14}$

Transporte, traslado, ingreso o salida por territorio nacional de dinero o títulos valores de origen ilícito

El Artículo $3^{\circ}$ del Decreto Legislativo 1106 tipifica como delito el "transporte, traslado, ingreso o salida por territorio nacional de dinero o títulos valores de origen ilícito”. El texto legal de dicho artículo es el siguiente:

"El que transporta o traslada dentro del territorio nacional dinero o títulos valores cuyo origen ilícito conoce o debía presumir, con la finalidad de evitar la identificación de su origen, su incautación o decomiso, o hace ingresar o salir del país tales bienes con igual finalidad, será reprimido con pena privativa de libertad no menor de ocho ni mayor de quince años y con ciento veinte a trescientos cincuenta días multa”.

El artículo en comento es una nueva modalidad incorporada a las ya existentes, como son "los actos de conversión y transferencia" y "actos de ocultamiento y tenencia”, innovación que incorpora el "transporte, traslado, ingreso o salida por territorio nacional de dinero o títulos valores de origen ilícito".

Objeto materia del delito: el objeto materia del delito es el objeto físico sobre el que recae la conducta delictiva, diferenciándose del objeto de protección penal o bien jurídico tutelado, el cual es un bien abstracto.

El presente decreto legislativo en comento se refiere al objeto materia del delito haciendo alusión al dinero, bienes, efectos o ganancia. Dicha noción del bien coincide con el Art. 1 de la Convención de Viena; consecuentemente, no ingresan a la noción de bienes comprendidos dentro del alcance del delito de lavado de activos aquellos objetos materiales e inmateriales que carecen de valoración económica o valor de cambio en el mercado; quedan así descartadas las cosas que solo poseen un valor afectivo o sentimental.

13 Víctor Roberto Prado Saldarriaga. Lavado de activos y financiación del terrorismo. Editorial Grijley, 2007, p. 143.

14 Víctor Roberto Prado Saldarriaga. Lavado de activos y financiación del terrorismo. Editorial Grijley, 2007, p. 146. 
Con respecto al sujeto activo, puede ser cualquier persona que cometa las conductas descritas en el párrafo anterior.

Con respecto al sujeto pasivo en el delito descrito, es la sociedad o comunidad en general.

\section{Circunstancias}

El artículo $4^{\circ}$ del Decreto Legislativo 1106 tipifica como delito las "circunstancias agravantes y atenuantes". El texto legal de dicho artículo es el siguiente:

"La pena será privativa de Libertad no menor de diez ni mayor de veinte años y trescientos sesenta y cinco a setecientos treinta días multa, cuando:

1. El agente utilice o se sirva de su condición de funcionario público o de agente del sector inmobiliario, financiero, bancario y bursátil.

2. El agente cometa el delito en calidad de integrante de una organización criminal.

3. El valor del dinero, bienes, efectos o ganancias involucrados sea superior al equivalente a quinientas (500) unidades impositivas tributarias.

La pena será privativa de la libertad no menor de veinticinco años cuando el dinero, bienes, efectos o ganancias provienen de la minería ilegal, tráfico ilícito de drogas, terrorismo, secuestro, extorsión o trata de personas.

La pena será privativa de la libertad no menor de cuatro ni mayor de seis años y de ochenta a ciento diez días multa, cuando el valor del dinero, bienes, efectos o ganancias involucrados no sea superior al equivalente a cinco (5) unidades impositivas tributarias. La misma pena se aplicará a quien proporcione a las autoridades información eficaz para evitar la consumación del delito, identificar y capturar a sus autores o partícipes, así como detectar o incautar los activos objeto de los actos descritos en los artículos $1^{\circ}, 2^{\circ}$ y $3^{\circ}$ del presente Decreto Legislativo".

Las circunstancias agravantes tienen la condición de especiales y específicas cuando su aplicación la define la norma, y son específicas solo para determinados delitos, como son:

1. El agente utilice o se sirva de su condición de funcionario público o de agente del sector inmobiliario, financiero, bancario y bursátil

Se trata de las circunstancias y vinculación del agente con una facultad o un deber especial derivado de su función o profesión. Justifican el mayor desvalor y punibilidad del comportamiento del delincuente. ${ }^{15}$

15 Víctor Roberto Prado Saldarriaga. Lavado de activos y financiación del terrorismo. Editorial Grijley, 2007, p. 166. 
La noción de funcionario público, de la que parte la ley, debe entenderse en un sentido amplio y no restringido ni formal como la definición administrativa de funcionario público. No solo los funcionarios vinculados a la carrera administrativa pueden cometer el delito (funcionario público stricto sensu), sino también otros agentes que se relacionan con la Administración Pública y ejercen función pública. Un parámetro interpretativo de suma utilidad que ayuda a delimitar la noción de funcionario público es el artículo $425^{\circ}$ del Código Penal, el mismo que le da el carácter de elemento normativo a este componente. La ley, a diferencia de otras normas penales referidas a agentes de la Administración Pública, solo toma en consideración a los funcionarios públicos, no así a los servidores públicos, tal vez por considerar que estos no tienen los mismos deberes o posición de garante frente a la Administración Pública, o porque las facultades de las que están investidos no resultan suficientes para realizar eficazmente las conductas típicas o porque con ellas no resultan totalmente potenciados como para lograr la impunidad de los delitos. Sin embargo, si se asumiera el criterio que considera que estos servidores también ejercen función pública (y no únicamente que prestan su concurso para que la ejerzan los funcionarios), no habría razón para excluirlos de la presente agravante. ${ }^{16}$

2. El agente cometa el delito en calidad de integrante de una organización criminal

Cuando nos referimos a una organización criminal no nos estamos refiriendo a cualquier estructura criminal, sino específicamente a la organización criminal dedicada al lavado de activos. La Convención de las Naciones Unidas Contra la Delincuencia Organizada Transnacional define al "grupo delictivo organizado" como un grupo estructurado de tres o más personas que exista durante cierto tiempo y que actúe concertadamente con el propósito de cometer uno o más delitos graves o delitos tipificados con arreglo a la presente convención, con miras a obtener, directa o indirectamente, un beneficio económico u otro beneficio de orden material (Art. 2, Inc. a).

La idea de organización queda satisfecha cuando se logra establecer una formal o material distribución de funciones entre los miembros, determinando los deberes y derechos de cada uno de ellos, como la actividad que ha de cumplir, y además exista por lo menos una elemental estructura jerárquica entre los asociados, señalando un determinado mando y rango, ya sea personal o colegiado, y una determinada línea de acción vertical basada en el compromiso, elemental lealtad y obediencia respecto a los acuerdos comunes. ${ }^{17}$

Las circunstancias atenuantes, por su parte, consideran que:

1. El valor del dinero, bienes, efectos o ganancias involucrados sea superior al equivalente a quinientas (500) unidades impositivas tributarias

16 Tomas Aladino Gálvez Villegas. El delito de lavado de activos. Editorial Jurídica Grijley, 2004, p. 79.

17 Ibidem. p. 82. 
La circunstancia atenuante en este delito se ve reflejada con un mínimo de penas conjuntas de cuatro a seis años de pena privativa de libertad de 80 a 110 días multa en los siguientes supuestos:

- Cuando el valor del dinero, bienes, efectos o ganancia involucrados no sea superior al equivalente a 5 unidades impositivas tributarias. Consideramos que con estas circunstancias referidas al monto involucrado se consolida más el principio de proporcionalidad respecto a las penas fijadas por este delito.

- Cuando el agente proporcione a las autoridades información eficaz para evitar la consumación del delito, identificar y capturar a sus autores y participes, así como detectar o incautar los activos objeto de los actos descritos en los artículos 1, 2 y 3 de la nueva norma. Aquí podemos apreciar que el legislador optó por insertar un claro componente del Derecho Penal preliminar y de las políticas de lucha contra la criminalidad organizada: la colaboración eficaz. $^{18}$

\section{Omisión de comunicación de operaciones o transacciones sospechosas}

El artículo $5^{\circ}$ del Decreto Legislativo 1106 tipifica como delito la "omisión de comunicación de operaciones o transacciones sospechosas". El texto legal de dicho artículo es el siguiente:

"El que incumpliendo sus obligaciones funcionales o profesionales, omite comunicar a la autoridad competente, las transacciones u operaciones sospechosas que hubiere detectado, según las leyes y normas reglamentarias, será reprimido con pena privativa de la libertad no menor de cuatro ni mayor de ocho años, con ciento veinte a doscientos cincuenta días multa e inhabilitación no menor de cuatro ni mayor de seis años, de conformidad con los incisos 1), 2) y 4) del artículo 36 del Código Penal.

La omisión por culpa de la comunicación de transacciones u operaciones sospechosas será reprimida con pena de multa de ochenta a ciento cincuenta días multa e inhabilitación de uno a tres años, de conformidad con los incisos 1), 2) y 4) del Art. 36 del Código Penal”.

Por otro lado, el ilustre jurista Paucar $\mathrm{Chapa}^{19}$ considera que esta disposición viene a ser un tipo penal en blanco, por la necesidad de recurrir a una norma extrapenal para integrar sus elementos de tipicidad. Así:

a) Para identificar a los sujetos obligados al reporte se debe tomar en cuenta a los 32 entes en lista en el Art. 8 de la Ley No 27693 (modificado por Ley No 28306).

18 Marcial Eloy Paucar Chappa. "La Nueva Ley Penal de Lavado de Activos: El Decreto Legislativo N 1106”. En: Gaceta Penal y Procesal Penal. No 35, mayo 2012, pp. 73.

19 Marcial Eloy Paucar Chappa. "La Nueva Ley Penal de Lavado de Activos: El Decreto Legislativo N 1106". En: Gaceta Penal y Procesal Penal. No 35, mayo 2012, pp. 74. 
b) Para conocer qué operaciones y transacciones sospechosas tienen dicha condición, se ha de analizar lo establecido en el Art. 11.2 del Decreto Supremo No 018-2006-JUS (Reglamento de la Ley 27693), que señala:

"Constituye operación sospechosa aquella operación detectada como inusual y que, en base a la información con que cuenta el sujeto obligado de su cliente, lo lleve a presumir que los fondos utilizados en esa operación proceden de alguna actividad ilícita por carecer de fundamento económico o legal aparente”.

Es importante señalar que en un inciso solo estaban vinculadas las entidades bancarias o financieras, conforme lo establecían los artículos 375 y siguientes de la Ley Nº 26702 (Ley General del Sistema Financiero y del Sistema de Seguros y Orgánica de la Superintendencia de Banca y Seguros) y sus modificatorias posteriores, referidas a transacciones financieras sospechosas.

c) Para establecer cuál es el plazo que tiene el agente para realizar el reporte, también se deberá recurrir al artículo 11.1 del citado cuerpo normativo, el cual establece:

"Los sujetos obligados a informar deben comunicar a la UIF-Perú las operaciones sospechosas que detecten en el curso de sus actividades, sin importar los montos involucrados, en un plazo no mayor de 30 días calendario, contado desde la fecha en que estas han sido detectadas".

\section{Rehusamiento, retardo y falsedad en el suministro de información}

El artículo $6^{\circ}$ del decreto legislativo 1106 tipifica como delito el "rehusamiento, retardo y falsedad en el suministro de información”. El texto legal de dicho artículo es el siguiente:

"El que rehúsa o retarda suministra a la autoridad competente, la información económica, financiera, contable, mercantil o empresarial que le sea requerida, en el marco de una investigación o juzgamiento por delito de lavado de activos, o deliberadamente presta la información de modo inexacto o brinda información falsa, será reprimido con pena privativa de la libertad no menor de dos años ni mayor de cuatro años, con cincuenta a ochenta días multa e inhabilitación no mayor de tres años de conformidad con los incisos 1), 2), y 4) del Artículo 36 del Código Penal.

Si la conducta descrita se realiza en el marco de una investigación o juzgamiento por delito de lavado de activos vinculado a la minería ilegal o al crimen organizado, o si el valor del dinero, bienes, efectos o ganancias involucradas es superior al equivalente a quinientas (500) unidades impositivas tributarias, el agente será reprimido con pena privativa de libertad no menor de tres ni mayor de cinco años, con ochenta a ciento cincuenta días multa e inhabilitación no mayor de cuatro años, de conformidad con los incisos 1), 2) y 4) del artículo $36^{\circ}$ del Código Penal.” 
El ilustre jurista Paucar Chappa considera que para que el tipo penal en este delito se concrete, bastará con que el agente realice cualquiera de las tres conductas, como puede ser "rehusar" o "retardar" el suministro de información calificada o "brindar información inexacta o falsa”. En cuanto a las dos primeras modalidades, la información a la que se hace referencia puede ser de diferente naturaleza, ello por un fundamento teleológico muy importante: es necesario entender que el lavado de activos es un proceso económico, financiero y contable que busca dar apariencia de legitimidad a dinero o bienes de origen ilícito; por tal razón, dicha disposición subraya en forma enunciativa que el tipo de información requerida reviste esas características. Con respecto a la tercera modalidad: "brindar" deliberadamente información inexacta o falsa, el elemento subjetivo "deliberadamente" es una conducta dolosa, y nunca puede ser culposa.

Otra innovación resaltante en el artículo en comento es la circunstancia agravante que comprende dos supuestos: ${ }^{20}$

1. "Se realiza en el marco de una investigación o juzgamiento por delito de lavado de activos vinculado a la minería ilegal o al crimen organizado". Para que opere esta agravante será necesario que el delito precedente sea el de minería ilegal (regulado en el Decreto Legislativo 1102) o, en su defecto, un delito de criminalidad organizada, siendo necesaria la corroboración de actividades delictuosas relacionadas con una organización criminal, para lo cual ha de considerarse como criterio hermenéutico válido que dicha verificación se realice en función de los supuestos típicos del delito sancionado en el Art. 317 del Código Penal (integración a una organización criminal) o de aquellos delitos en cuyas circunstancias agravantes se encuentre prevista la existencia de una organización criminal.

2. Si el valor del dinero, bienes efectos o ganancias involucrados es superior al equivalente a 500 UIT. Dicho monto es el mismo que se encuentra en el inciso 3 del Art. 4 del Decreto Legislativo $\mathrm{N}^{\circ} 1106$.

\section{Reglas de investigación}

El artículo $7^{\circ}$ del Decreto Legislativo 1106 define las “reglas de investigación”. El texto legal de dicho artículo es el siguiente:

"Para la investigación de delitos previstos en el presente Decreto Legislativo, el Fiscal podrá solicitar al Juez el levantamiento del secreto bancario, el secreto de las comunicaciones, la reserva tributaria, y la reserva bursátil. La información obtenida en estos casos solo será utilizada en relación con la investigación de los hechos que la motivaron”.

20 Marcial Eloy Paucar Chappa. "La Nueva Ley Penal de Lavado de Activos: El Decreto Legislativo N 1106”. En: Gaceta Penal y Procesal Penal. No 35, mayo 2012, pp. 76-77. 
Estas medidas se justifican solo si son necesarias para facilitar la investigación y la prueba del delito imputado, ya sea verificando transacciones efectuadas a través del sistema de intermediación financiera o revisando las operaciones económicas o bursátiles realizadas por las personas implicadas. Por consiguiente, solo se justifica excluir del secreto bancario o de las reservas tributarias y bursátiles a aquellos clientes o usuarios sobre los que concurran indicios razonables de estar realizando operaciones de lavado de activos. ${ }^{21}$

\section{Consecuencias accesorias aplicables a personas jurídicas}

El artículo $8^{\circ}$ del Decreto Legislativo 1106 tipifica las "consecuencias accesorias aplicables a personas jurídicas". El texto legal de dicho artículo es el siguiente:

"Si los delitos contemplados en los artículos 1, 2 y 3 del presente Decreto Legislativo fueren cometidos en ejercicio de la actividad de cualquier persona jurídica o utilizando su organización o servicios, para favorecerlos o encubrirlos, el Juez deberá aplicar, según la gravedad y naturaleza de los hechos o la relevancia de la intervención en el hecho punible, las siguientes consecuencias accesorias de manera alternativa o conjunta:

1. Multa con un valor no menor de cincuenta ni mayor de tres unidades impositivas tributarias.

2. Clausura definitiva de locales o establecimientos.

3. Suspensión de actividades por un plazo no mayor de tres años.

4. Prohibición de realizar en el futuro actividades de la clase de aquellas en cuyo ejercicio se haya cometido, favoreciendo o encubriendo el delito.

5. Cancelación de licencia, derechos y otras autorizaciones administrativas o municipales.

6. Disolución de la persona jurídica.

Simultáneamente a la medida impuesta, el Juez ordenará a la autoridad competente que disponga la intervención de la persona jurídica para salvaguardar los derechos de los trabajadores y de los acreedores, hasta por un período de dos años.

El cambio de la razón social o denominación de la persona jurídica o su reorganización societaria, no impide la aplicación de estas medidas".

Gálvez Villegas refiere que cometido el delito, o acreditada su comisión, las consecuencias que de ello se derivan pueden ser de doble naturaleza. Las primeras están referidas a las

21 Víctor Roberto Prado Saldarriaga. Lavado de activos y financiación del terrorismo. Editorial Grijley, 2007, p. 183. 
consecuencias personales del agente del delito, y las segundas, a las consecuencias patrimoniales o reales del delito, esto es, las vinculadas con los efectos y ganancias provenientes del delito, las vinculadas al objeto del delito y a los instrumentos y, en ciertos casos, al de terceros vinculados al hecho delictivo a la persona del agente. ${ }^{22}$

Lo transcendental y novedoso en el presente decreto legislativo en comento es la responsabilidad penal que se incorpora en las personas jurídicas, disposición que proviene de lo establecido en el artículo 105 del Código Penal, concretándose para ello las consecuencias accesorias interpuestas por el artículo en comento.

\section{Decomiso}

El artículo $9^{\circ}$ del Decreto Legislativo 1106 tipifica el "decomiso". El texto legal de dicho artículo es el siguiente:

"En todos los casos, el Juez resolverá la incautación o el decomiso del dinero, bienes, efectos o ganancias involucrados, conforme a lo previsto en el Art. 102 del Código Penal”.

El comiso o decomiso se conceptúa "como la pérdida de los efectos o instrumentos de la infracción punitiva y el correlativo traslado directo e inmediato de su titularidad a favor del Estado", dictado por autoridad jurisdiccional, previo un debido proceso y la observancia de todas las garantías legales correspondientes. Agregamos nosotros, aun cuando existe el llamado comiso administrativo, el mismo que en calidad de sanción administrativa se impone a los autores de infracciones (no constitutivas de delito) a la Ley de Delitos Aduaneros $\mathrm{N}^{\circ}$ 28008, las normas municipales y las relativas a la defensa de la propiedad intelectual, cuya competencia para imponerlas precisamente la tiene la Superintendencia Nacional de Aduanas, las municipalidades y el INDECOPI, respectivamente. ${ }^{23}$

Comoquiera que el comiso significa la pérdida de "derechos reales" que pudiera tener el agente del delito sobre bienes decomisables, los cuales pasan a la titularidad del Estado, el mismo debe realizarse respetando todas las garantías correspondientes a la defensa y protección de los derechos fundamentales de la persona humana, ya que las distintas Constituciones Política de los diversos Estados y la nuestra en particular, en el inciso 16 de su artículo $2^{\circ}$, asignan al derecho de propiedad esta calidad. ${ }^{24}$

\section{Autonomía del delito y prueba indiciaria}

El artículo $10^{\circ}$ del Decreto Legislativo 1106 tipifica la “autonomía y prueba indiciaria”. El texto legal de dicho artículo es el siguiente:

22 Tomas Aladino Gálvez Villegas. El delito de lavado de activos. Editorial Jurídica Grijley, 2004, p. 154.

23 Tomas Aladino Gálvez Villegas. El delito de lavado de activos. Editorial Jurídica Grijley, 2004, p. 157.

24 Tomas Aladino Gálvez Villegas. El delito de lavado de activos. Editorial Jurídica Grijley, 2004, p. 158. 
"El lavado de activos es un delito autónomo por lo que para su investigación y procedimiento no es necesario que las actividades criminales que produjeron el dinero, los bienes, efectos o ganancias, hayan sido descubiertas, se encuentran sometidas a investigación, proceso judicial o hayan sido previamente objeto de prueba o de sentencia condenatoria.

El conocimiento del origen ilícito que tiene o que debía presumir el agente de los delitos que contemplan el presente Decreto Legislativo, corresponde a actividades criminales, como los delitos de minería ilegal, el tráfico ilícito de drogas, el terrorismo, los delitos contra la administración pública, el secuestro, el proxenetismo, la trata de personas, el tráfico ilícito de armas, tráfico ilícito de migrantes, los delitos tributarios, la extorsión, el robo, los delitos aduaneros o cualquier otro con capacidad de generar ganancias ilegales, con excepción de los actos contemplados en el Art. $194^{\circ}$ del Código Penal. El origen ilícito que conoce o debía presumir el agente del delito podrá inferirse de los indicios concurrentes en cada caso.

También podrá ser considerado autor del delito, y por tanto sujeto de investigación y juzgamiento por lavado de activos, quien ejecutó o participó en las actividades criminales generadoras del dinero, bienes, efectos o ganancias".

Entre las principales innovaciones que presenta el Decreto Legislativo 1106 está su artículo 10, donde se encuentra la prescripción expresa del delito de lavado de activos como un tipo penal autónomo. Con ello se busca hacer efectiva la persecución penal de las personas que cometan actividades de lavado sin la necesidad de que las conductas criminales que produjeron los activos ilícitos (los bienes, efectos o ganancias) hayan sido descubiertas, se encuentren sometidas a investigación o proceso judicial, o hayan sido previamente objeto de prueba o de sentencia condenatoria. ${ }^{25}$

Asimismo, se señala que el conocimiento del origen ilícito que tiene o debía presumir el agente corresponde a actividades criminales como los delitos de minería ilegal, el tráfico ilícito de drogas, el terrorismo, los delitos contra la administración pública, el secuestro, el proxenetismo, la trata de personas, el tráfico ilícito de armas, el tráfico ilícito de migrantes, los delitos tributarios, la extorsión, el robo, los delitos aduaneros o cualquier otro con capacidad de generar ganancias ilegales, con excepción de los actos contemplados en el Art. 194º. El origen ilícito que conoce o debía presumir el agente del delito podrá inferirse de los indicios concurrentes en cada caso. ${ }^{26}$

La redacción y la forma en que se ha delineado el artículo $10^{\circ}$ del Decreto Legislativo $N^{\circ} 1106$, en nuestro humilde entender y criterio, resulta ser un otorgamiento de excesivas

25 Jorge Pérez López. "Lavado de activos sustantivos del Decreto Legislativo № 1106". En: Gaceta Penal y Procesal Penal. $\mathrm{N}^{\circ} 35$, mayo 2012, p. 61.

26 Ibidem. p. 62. 
facultades para el accionar policial y actuación del representante del Ministerio Público, que vulneran principios constitucionales como el de presunción de inocencia, por cuanto se puede someter a una investigación por el delito de lavado de activos a una persona por solo tener "indicios", los que muchas veces se construyen sobre la base de los famosos informes de inteligencia policial provenientes de "fuente humana", resultando en muchos de los casos otorgados por personas que, promovidas por espíritu de revanchismo, envidia, venganza, egoísmo, etc. contra el investigado, no dudan en imputar actos delictivos a su adversario de forma directa o por intermedio de terceras personas, amparados en el anonimato, dando origen a la promoción de una acción penal injusta basada en conjeturas. Así ocurre que estas acciones penales solo llegan a engrosar la larga lista de procesos judiciales que terminan con la absolución o sobreseimiento de las mismas por falta de pruebas, con el agravante de que la persona sometida a investigación por lavado de activos de esta forma no solo pierda su patrimonio económico, sino que además pierda lo más valioso que tiene, su honra y dignidad, deshonra que nada ni nadie, ni la mejor indemnización, va a restablecer.

También nos preocupa que como consecuencia de la autonomía y de la prueba indiciaria, se someta a investigación por lavado de activos a personas naturales y jurídicas por el simple hecho de mostrar de manera externa un crecimiento de su patrimonio y posición social, sin conocer el lado interno de sus actividades económicas, en la medida que es de público conocimiento que frente a la estabilidad económica que tiene nuestro país, cada día existen mayores ofertas de acceso al crédito, ofertas que son tomadas por empresarios emprendedores para incursionar en el mercado, pero que, a mérito de los sentimientos egoístas antes descritos por sus enemigos o gente interesada en perjudicarlo, se pueden ver sometidos no solo a una investigación de lavado de activos sino de varias investigaciones al relacionarlos con otros delitos fuentes, en distintos lugares, y que dan origen a que el Fiscal provincial especializado en lo penal de distinto distrito judicial les promueva varias investigaciones en su contra, investigaciones que a su vez son derivadas a las unidades especializadas que cuentan con una división de lavado de activos, entrando en una beligerante contienda de competencia y exaltado protagonismo de querer llevar a cabo las investigaciones a costa de la vulneración de otros derechos, como el defensa, non in bis ídem, ordenando para ello la práctica de pericias contables simultaneas, a las que, de la forma como está delineado el Decreto Legislativo $\mathrm{N}^{\circ}$ 1106, el investigado debe someterse de manera inmediata, porque de lo contrario estaría incurriendo en el delito de "rehusamiento, retardo y falsedad en el suministro de información". Frente a esta preocupante situación, los legisladores deberán actuar para evitar que la norma materia de análisis se convierta en una norma peligrosa de irreparables consecuencia para los derechos fundamentes, garantías y principios constitucionales; por ello, se debe pensar en forma inmediata en una reglamentación que establezca reglas procedimentales y delinee las actuaciones de las instituciones a cargo de las investigaciones. 
Lo antes manifestado debe despertar nuestra preocupación por la defensa del empresariado honesto que día a día viene apostando por nuestro Perú, pero que en las disposiciones contenidas en el Decreto Legislativo $\mathrm{N}^{\circ} 1106$ ve una arma de doble filo, porque no solo se pretende combatir el delito de lavado de activos que tanto daño hace a la economía del país, sino que además también puede ser usada en su contra por sus competidores para sacarlo del mercado mediante imputaciones genéricas como son las pruebas indiciarias; por ello, es necesario que las investigaciones que se inicien por la presunta comisión del delito de lavado de activos se hagan teniendo en cuenta los informes de la unidad de inteligencia financiera y no solamente en base a cuestionados informes de inteligencia con el carácter de "secreto", los que, como volvemos a repetir, a veces tienen como base los imputaciones de carácter subjetivo de informantes llamados "fuente humana", y no pruebas objetivas. Con esto se fortalecerá la defensa de los derechos humanos y la observancia de las garantías penales que nuestra legislación contempla en el artículo VII del Título Preliminar del Código Penal. Actuar sin observancia de estas disposiciones elementales es retroceder a acciones vedadas del pasado y que tanto daño han hecho al país.

No podemos dejar de expresar que a poco más de un año y medio de la expedición del Decreto Legislativo 1106, el 16 de mayo del 2013 se ha expedido el Oficio Circular N ${ }^{\circ}$ 024-2013-MP-FN-SEGFIN, dirigido a los Presidentes de la Junta de Fiscales Superiores a nivel nacional, expresando lo siguiente:

“(..) que, conforme a lo establecido en el artículo 10 del Decreto Legislativo $\mathrm{N}^{\circ} 1106$ Decreto Legislativo de Lucha eficaz contra el lavado de activos y otros delitos relacionados a la minería ilegal y crimen organizado, el lavado de activos es un delito autónomo, y no tiene delito fuente, por lo que para su investigación y procesamiento no es necesario que las actividades criminales que produjeron el dinero, los bienes, los efectos o ganancias, hayan sido descubiertas, se encuentren sometidas a investigación, proceso judicial o hayan sido previamente objeto de prueba o de sentencia condenatoria (...) se sirvan instruir a los señores fiscales a cargo de las investigaciones sobre lavado de activo de cada uno de sus distritos fiscales, con la finalidad que se dé estricto cumplimiento a lo dispuesto por dicha norma, bajo responsabilidad de comunicar a las Fiscalías Desconcentradas de Control Interno la no observancia de la misma (..).

Ante ello, Paucar Chapa ${ }^{27}$ refiere que de la presente disposición de la Fiscalía de la Nación se desprenden las siguientes conclusiones concretas y específicas: i) luego de varios obstáculos, finalmente la máxima autoridad del Ministerio Público ha tomado la decisión, en el marco de sus atribuciones, de instruir a los Fiscales de todas las instancias a rechazar laminarmente

27 Marcial Eloy Paucar Chapa. "El delito precedente en el lavado de activos: comentarios a la luz del Oficio Circular Nro. 024-2013-MP-FN-SEGFIN”. En: Gaceta Penal y Procesal Penal. Tomo 49, julio 2013. 
el delito fuente como requisito para la tipificación, sobre todo al inicio de las investigaciones; ii) el incumplimiento de la norma penal (artículo 10 del Decreto Legislativo $\mathrm{N}^{\circ} 1106$ ) va a acarrear responsabilidad ante las Fiscalías Descentralizadas de Control interno, siendo importante que el Poder Judicial adopte dicha conminación de aplicabilidad obligatoria normativa a los jueces, claro está, también bajo responsabilidad. Con lo anterior, pues, se ha ratificado y fortalecido la posición de la doctrina, que, desde siempre, defendió dicha postura.

\section{CONCLUSIONES}

1. Gálvez Villegas ${ }^{28}$ señala que la actividad criminal está orientada en esencia a producir grandes cantidades de recursos económicos para sus agentes, los que en parte son destinados a financiar otras actividades delictivas, con el consecuente efecto multiplicador en cadena de la actividad criminal.

2. Calderón Valverde ${ }^{29}$ establece que como consecuencia del desarrollo de la minería ilegal se pueden identificar claramente determinadas conductas criminales, como son los delitos de lavado de activos, contrabando, evasión tributaria, corrupción en todas sus formas, trata de personas, entre otros. En resumidas cuentas, constituye una actividad con una severa repercusión y reproche social por la variedad y gravedad de sus efectos.

3. Por ello, son muchas las formas por las cuales los países han buscado firmemente el medio de combatir el lavado de dinero, sobre todo los países subdesarrollados. La creación de variadas organizaciones para luchar contra estas malas prácticas financieras, como por ejemplo el Gafisud, se ha constituido en un gran avance para que las naciones se reúnan y pongan mano firme frente al lavado de dinero y muchos otros delitos fiscales que afectan a nuestra sociedad.

4. Saldaña Pineda ${ }^{30}$ establece que en el caso peruano se advierte que la presión del control estatal u oficial sobre el lavado de activos es baja, lo que evidencia la reducida cantidad de investigaciones que llegan a las autoridades fiscales y judiciales. Si a ello agregamos la poca frecuencia de procesos judiciales en trámite y el número mínimo de casos que han sido resueltos por el Poder Judicial, resulta más que evidente que el control del lavado de activos no está siendo eficaz ni eficiente. Parece olvidarse que el delito de lavado de activos constituye un ilícito de carácter pluriofensivo, que pone en estado de peligro las bases sociales y la propia existencia del Estado.

28 Tomás Gálvez Villegas. El delito de lavado de activos. Lima: Juristas Editores, 2009, p. 20.

29 Leonardo Calderón Velarde. "Apuntes sobre el delito de minería ilegal en el Perú a poco más de un año desde su tipificación”. En: Gaceta Penal y Procesal Penal. Tomo 49, julio 2013, p. 165.

30 Róger Saldaña Pineda. "La autonomía del delito de lavado de activos". En: Gaceta Penal y Procesal Penal. Tomo 48, junio 2013, p. 176. 
5. Consecuentemente, se hace necesario reglamentar las actuaciones procedimentales tanto del despacho fiscal especializado como del personal policial a cargo de las investigaciones, para evitar someter a los investigados a más de una investigación por los mismos hechos. Así mismo, se sugiere establecer un ente rector que centralice la información financiera de los administrados con capacidad de realizar acciones previas de control, a fin de no solo prevenir el delito sino también, de advertirse actuaciones irregulares que merezcan una actuación inmediata de los órganos jurisdiccionales, solicitar en forma inmediata la intervención del representante del Ministerio Público para el ejercicio de sus atribuciones, acción que permitirá, además de un combate rápido y eficaz del delito, evitar acciones de investigación fiscal y policial en base a pruebas indiciarias que a la postre conllevan a la expedición de fallos absolutorios o al sobreseimiento de la acción penal.

6. En este último punto, el Nuevo Código Procesal Penal 2004 va a ayudar a prevenir acciones o procesos penales paralelos por un mismo hecho, pero bajo diferentes aristas, pues existe la mala praxis de empezar por una presunción de responsabilidad penal, de instaurar un subsecuente proceso penal por lavado de activos, pese a que por el delito fuente se absolvió a la persona vía interdicción de la persecución múltiple, en virtud de la cual "nadie podrá ser procesado, ni sancionado más de una vez, por un mismo hecho, siempre que se trate del mismo sujeto y fundamento" (artículo III del Título Preliminar del Código Procesal Penal). 


\section{REFERENCIAS}

- Bramont Arias-Torres, Luis y García Cantizano, María Del Carmen. Manual de Derecho Penal. Parte especial. Cuarta edición. Lima: San Marcos, 1998.

- Bramont-Arias Torres, Luis Alberto. "Algunas precisiones referentes a la Ley Penal contra el Lavado de Activos. Ley 27765, 27/06/2002”. En: Estudios penales. Libro homenaje al profesor Luis Alberto Bramont-Arias. Lima: San Marcos, 2003.

- Calderón Velarde, Leonardo. "Apuntes sobre el delito de minería ilegal en el Perú a poco más de un año desde su tipificación”. En: Gaceta Penal y Procesal Penal. Tomo 49, julio 2013.

- Gálvez Villegas, Tomás. El delito de lavado de activos. Lima: Juristas Editores, 2009.

- García Cavero, Percy. Derecho Penal Económico. Parte general. Primera edición. Lima, 2003.

- Greus, Carlos. Derecho Penal. Parte especial. Tomo 2. Buenos Aires: Editorial Astrea, De Alfredo y Ricardo Depalma, 1990.

- Hinostroza Pariachi, César. El delito de lavado de activos. Editorial Grijley, 2009.

- Irigoyen Fajardo, Raquel y Soberón Garrido, Luis Francia. Drogas y control penal en los Andes. Comisión Andina de Juristas, 1994.

- Lamas Puccio, Luis. "La ley penal contra el lavado de activos". En: Revista del Foro. Año XC, $\mathrm{N}^{\circ}$ 1, Colegio de Abogados de Lima, 2004.

- Lamas Puccio, Luis. Tráfico ilícito de drogas y lavado de dinero. Segunda edición. Librería y Ediciones Jurídicas, 1999.

- León Gamarra, Juan B. El contador público en la investigación del lavado de activos en el Perú. Lima: L y F Ediciones Jurídicas, 2003.

- Paucar Chapa, Marcial Eloy. "El delito precedente en el lavado de activos: comentarios a la luz del Oficio Circular Nro. 024-2013-MP-FN-SEGFIN”. En: Gaceta Penal y Procesal Penal. Tomo 49, julio 2013.

- Peña Cabrera Freyre, Alonso. Tráfico ilícito de drogas y delitos conexos. Perspectivas dogmáticas y politico-criminales. Lima: Juristas Editores, 2009.

- Pérez López, Jorge. "Lavado de activos sustantivos del Decreto Legislativo N 1106". En: Gaceta Penal y Procesal Penal. No 35, mayo 2012.

- Prado Saldarriaga, Víctor Roberto. Lavado de activos y financiación del terrorismo. Editorial Grijley, 2007. 
- Prado Saldarriaga, Víctor Roberto. El delito de lavado de dinero. Su tratamiento penal y Bancario en el Perú. Lima: IDEMSA, 1994.

- Saldaña Pineda, Róger. "La autonomía del delito de lavado de activos". En: Gaceta Penal y Procesal Penal. Tomo 48, junio 2013.

- Sequeros Sazatornil, Fernando. Tráfico ilícito de drogas ante el ordenamiento jurídico. Evolución normativa, doctrinal y jurisprudencial. Madrid, 2000.

- Zaffaroni, Raúl Eugenio. En torno de la cuestión penal. Montevideo, Buenos Aires, 2005. 